\title{
Biodiversidade, Sociedades e Estados: lições de cooperação em áreas protegidas transfronteiriças
}

\author{
Biodiversity, Societies, and States: cooperation lessons in transboundary \\ protected areas
}

\author{
Marcela Stüker Kropf ${ }^{1}$ \\ Silvia Lilian Ferro ${ }^{2}$ \\ Rogério Ribeiro Oliveira ${ }^{3}$
}

\begin{abstract}
Resumo
Áreas protegidas fronteiriças são importantes instrumentos de conservação da natureza, sendo emblemáticas das relações sociedade e natureza. Essas áreas possibilitam processos cooperativos e de integração política, social e cultural do território. A Europa é pioneira na criação, gestão integrada e certificação de áreas protegidas fronteiriças. Tendo em vista a possibilidade de uso desses instrumentos em casos brasileiros de gestão compartilhada com países limítrofes, foram visitadas seis áreas e realizadas entrevistas aos gestores. A pesquisa é qualitativa, seguindo metodologia de análise de conteúdo das falas. As áreas visitadas demonstram a valorização da cultura regional e local. $\mathrm{O}$ discurso dos gestores evidenciou elementos práticos da cooperação transfronteiriça, tais como objetivos, benefícios, e dificuldades. As principais recomendações para implantação de melhores níveis de cooperação foram a motivação constante e entendimento mútuo entre os envolvidos. A pesquisa destaca a importância social do patrimônio natural da conservação presente e futura dos atributos culturais e ecológicos.
\end{abstract}

Palavras-chave: Estados Nacionais. Conservação da Natureza. Patrimônio. Fronteiras.

\begin{abstract}
Border protected areas are important tools of nature conservation, and emblematic of the relations between society and nature. These areas enable cooperative processes and political, social, and cultural integration of the territory. Europe is pioneer in the creation, integrated management, and certification of border protected areas. Considering the possibility of using these instruments in Brazilian cases of shared management with countries on the frontier, six areas were visited and interviews were conducted with their managers. The research is qualitative, following the methodology of speeches content analysis. The areas indicate the enhancement of regional and local culture. Managers speech revealed
\end{abstract}

\footnotetext{
${ }^{1}$ Universidade Federal da Integração Latino-Americana, Instituto Latino-Americano de Ciências da Vida e da Natureza, Foz do Iguaçu, PR, Brasil. Pesquisadora associada so Laboratório de Biogeografia e Ecologia Histórica da PUC-RJ. marcela.kropf@unila.edu.br

2 Universidade Federal da Integração Latino-Americana, Instituto Latino-americano de Economia, Sociedade e Política, Foz do Iguaçu, PR, Brasil. lilian.ferro@unila.edu.br

${ }^{3}$ Pontifícia Universidade Católica do Rio de Janeiro (PUC-RJ), Departamento de Geografia, Rio de Janeiro, RJ, Brasil. rro@puc-rio.com.br

Artigo recebido em: 24/10/2018; Aceito em: 22/04/2019.
} 
practical elements of transboundary cooperation, such as objectives, benefits, and difficulties. The main recommendations for implementing better levels of cooperation are the sustained motivation and mutual understanding among those involved. The research highlight the social importance of the natural heritage, the present and future conservation of the cultural and ecological attributes.

Keywords: National States.Nature Conservation. Heritage. Borders.

\section{Introdução}

O compartilhamento do patrimônio natural e a análise do espaço em escalas ampliadas inspiraram a formulação de novos instrumentos de gestão da biodiversidade como as áreas protegidas transfronteiriças, onde a cooperação na gestão de áreas protegidas adjacentes a dois ou mais países é o elemento-chave para caracterizá-las (IUCN, 1997; VASILIJEVIĆ, 2012). A cooperação transfronteiriça pode trazer muitos benefícios para a proteção do patrimônio natural e cultural de uma região (HAMILTON et al.,1996; DANBY 1997; KROPF; OLIVEIRA, 2013; SLOCOMBE; DANBY, 2006; VASILIJEVIĆ, 2012). A gestão transfronteiriça do patrimônio natural dos Estados carrega desafios especiais devido à diversidade de marcos institucionais e processos históricos particulares que impactam nos diferentes níveis de políticas públicas de conservação da biodiversidade.

Cada caso de cooperação conjunta para proteção e conservação de ecossistemas sob duas ou mais soberanias nacionais fornece uma oportunidade significativa de conhecimento e análise comparativa, visando selecionar aprendizados possíveis de adaptação em outros casos. Devido à contemporaneidade deste instrumento são relevantes estudos sobre a realidade prática da gestão, como também abordagens relativas ao paralelismo entre a diversidade cultural e a biológica.

O objeto desta pesquisa foram as áreas protegidas fronteriças (Internationally Adjoining Protected Areas - IAPA) do leste europeu, pelo histórico milenar do estabelecimento de fronteiras nesse continente, seu pioneirismo na conservação da natureza na região fronteiriça, apresentando 
o maior número de unidades mundiais de IAPA (UNEP, 2013), pela existência de diferentes estratégias de proteção ambiental a partir da formação de redes, por possuir certificação da cooperação das áreas protegidas transfronteiriças e pela existência da União Europeia como organização supranacional de estímulo à cooperação. Estas características permitem análise da cooperação entre as áreas que pode gerar subsídios para iniciativas similares no Brasil, país com extensa área fronteiriça (15.719 km) limitada com dez países, nove sulamericanos e um território francês de ultramar (GOES FILHO, 2013), compartilhando grandes extensões de florestas relativamente preservadas

Portanto, é objetivo deste trabalho apresentar o tema da conservação das áreas protegidas em fronteiras, numa perspectiva comparada da realidade prática da gestão cooperada no continente europeu, desde a percepção dos gestores, que possam ser lições e aprendizados aplicáveis no Brasil.

\section{Metodologia}

A revisão da literatura permitiu selecionar experiências relevantes de cooperação entre áreas protegidas transfronteiriças. Destacaram-se áreas com cooperação certificadas por um processo denominado Following Nature Design, implementado pela EUROPARC Federation, ONG cujo objetivo é melhorar a gestão das áreas protegidas na Europa (EUROPARC, 2010). O programa é realizado dentro uma rede de conexão entre os gestores das áreas certificadas, denominado TransParcNet. São nove complexos transfronteiriços certificados (EUROPARC, 2018), cinco desses selecionados para esta pesquisa após visita à sede da instituição, na cidade de Regensburg (Alemanha). Ainda incluímos como parte do estudo o projeto denominado Danube Parks, pois embora não possua certificação, tem alcance transnacional, e de grande relevância na Europa. 
Ao todo foram visitadas sete áreas protegidas e respectivos centros de visitantes (Mapa 1), entre os meses de fevereiro a maio de 2013: Parque Nacional Saxon Switzerland (Nationalpark Sächsische Schweiz), na cidade de Bad Schandau, na Alemanha; Parque Natural do Prealpi Giulie (Parco Naturale delle Prealpi Giulie), na cidade de Resia, Itália; Parque Nacional Triglav (Nacionalni Park Triglav), em Bled, na Eslovênia; Parque Nacional Krkonoše (Krkonoše Národní Park), na cidade de Vrchlabí, na República Checa; Parque Nacional Neusiedler See (Nationalpark Neusiedler See), cidade de Illmitz, Áustria; Parque Nacional Thayatal (National Lark Thayatal), em Hardegg, Áustria; Parque Nacional Donau-Auen (Nationalpark Donau-Auen), localizado na cidade de Orth, na Áustria.

Mapa 1 - Áreas Protegidas Transfronteiriças visitadas.
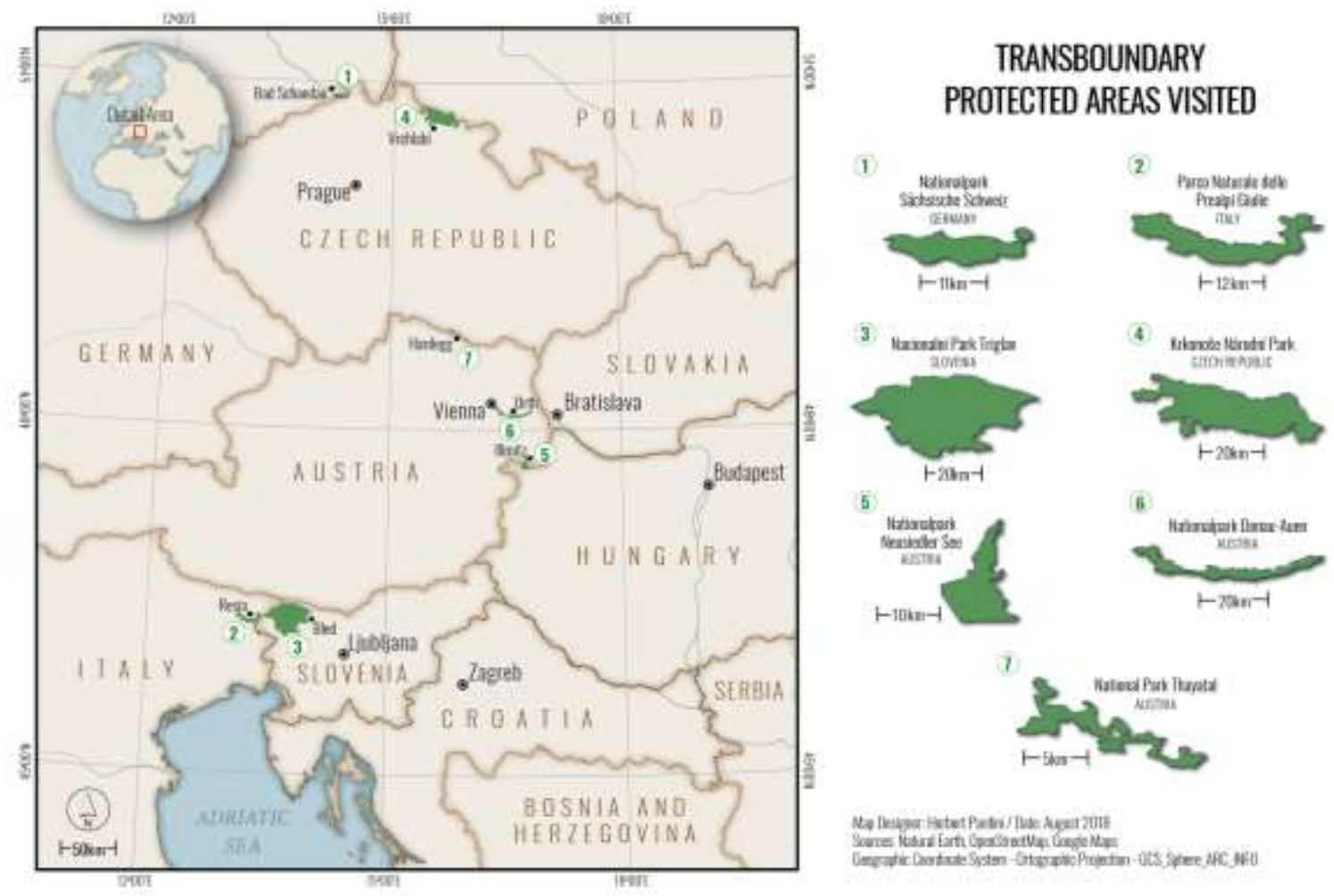

Fonte: Org. dos Autores, 2018. 
Entrevistas aos gestores de pelo uma das áreas protegidas de cada complexo fronteiriço permitiram acessar suas percepções acerca de diferentes aspectos da cooperação e situar o tema desde a realidade vivida por eles. As entrevistas semiestruturadas, compostas por questões abertas e fechadas, totalizaram 14 horas, sendo transcritas e traduzidas. Foi realizada a análise de conteúdo que, segundo Bardin (1997), é um conjunto de técnicas de análise das comunicações, visando obter, por procedimentos objetivos e sistemáticos de descrição do conteúdo das mensagens, indicadores (quantitativos ou não) que permitam a inferência de conhecimentos relativos às condições de produção/recepção destas mensagens. O software QSR International's NVivo 10 (NVIVOQUALITATIVE, 2012), auxiliou na categorização do conteúdo, visando determinar as diferentes visões sobre a cooperação transfronteiriça.

\section{Paradigma de conservação: características locais, continentais e globais}

Abordagem Ecossistêmica é o conjunto de princípios e diretrizes de integração de modelos de gestão e outras metodologias para lidar com a complexidade inerente à conservação da biodiversidade. A implementação varia de acordo com as condições locais, provinciais, regionais, nacionais ou globais, uma vez que a limitação do ecossistema é determinada pela unidade de análise. Smith e Maltby (2003) indicam cinco pontos operacionais principais da abordagem: (1) Focar nas relações e processos dentro dos ecossistemas; (2) Aumentar o compartilhamento de benefícios; (3) Utilizar práticas de gestão adaptativa; (4) Realizar ações de gestão numa escala apropriada, com descentralização para níveis mais baixos, conforme o caso; (5) Assegurar a cooperação entre setores.

Este enfoque auxilia na determinação de uma estrutura para a gestão de áreas protegidas pensada regionalmente, mesmo quando ultrapassa os limites nacionais, sendo forte argumento para o estabelecimento de uma 
estratégia de conservação de ecossistemas que ultrapassam fronteiras - a Conservação Transfronteiriça. As unidades de áreas protegidas são os pontos focais deste processo de integração da paisagem - também denominadas de Internationally Adjoining Protected Areas (IAPA) (Mittermeier et. al., 2005). Criar áreas na fronteira, principalmente adjacentes uma a outra, auxilia na conservação dos ecossistemas, devido à ampliação da área territorial protegida, porém, é necessário um trabalho conjunto entre os países para se obter uma gestão integrada, com base em trabalho articulado por protocolos de atuação conjunta, comunicação e cooperação entre as partes.

Verificam-se diferentes designações para representar as áreas protegidas fronteiriças. A Transboundary Conservation Area / Transboundary Conservation / Conservation Initiative -TCA, designa áreas e processos geográficos onde a cooperação através das fronteiras surge com o propósito específico de alcançar objetivos conservacionistas (VASILIJEVIĆ, 2012). Transboudary Protected Area (TBPA) é o termo mais aceito para designar áreas protegidas adjacentes a limites internacionais onde existe alguma forma de cooperação (SANDWICH et al., 2001). Irving (2004) destaca para a utilização deste termo para áreas contíguas que teriam uma gestão efetivamente (oficialmente) compartilhada. No entanto, os instrumentos legais de formalização da cooperação podem variar e por vezes restringirem-se a memorandos entre as duas áreas e não necessariamente entre governos.

A legitimidade da cooperação é o mais importante para definir as áreas protegidas transfronteiriças, ou seja, o reconhecimento de que ocorrem processos cooperativos entre seus gestores ou público em geral, mesmo sem a existência de acordos oficiais entre países (KROPF; OLIVEIRA, 2013). Esta definição é sustentada pela existência de diferentes níveis e formas de cooperação e formalização. Existem casos de áreas protegidas em fronteira 
que apresentam alta cooperação entre os gestores em sua prática diária, mas não estão formalizadas em nível governamental.

A International Union for Nature Conservation (IUCN) destaca que a cogestão, processo em que um número de interessados negocia responsabilidade sobre a gestão de uma área (IUCN, 1997), como prérequisito fundamental para a área a ser considerada conceitualmente como transfronteiriça (VASILIJEVIĆ, 2012). Existem outras definições para TBPA, sendo importante mencionar a adotada pela EUROPARC Federation, em que a TBPA é uma área composta por duas ou mais áreas protegidas localizadas dentro de território de dois ou mais Estados, adjacentes à fronteira, cada uma permanecendo sob a jurisdição da respectiva parte.

Esta definição não explicita a cooperação, no entanto, alguns trabalhos (DANBY, 1997; SLOCOMBE; DANBY 2006; HAMILTON et al., 1996; VASILIJEVIĆ, 2012) demonstram que não cooperar significa menor capacidade para resolver crises ou ameaças nas áreas, maior risco em não atingir os objetivos de conservação, menor potencial para captação de recursos, maior dispêndio de recursos, menor preparação para possíveis alterações decorrentes da incerteza das mudanças climáticas, posicionamento alheio às relações ecológicas e consequências disso, ineficiência e abuso de atividades ilegais e insegurança em zonas fronteiriças, aumenta a indisposição e dificulta a solução dos diversos conflitos que surgem quando as políticas de conservação se mostram distintas em cada país.

Embora a cooperação não possa ser imposta, pode ser sugerida, encorajada e nutrida por organizações e agências internacionais. Instituições podem atuar através da educação (ideias e valores), provendo capacitação de lideranças, tecnologias, pesquisa, eventos e ampliando as relações. Algumas organizações se destacam: IUCN, com o grupo de especialistas em conservação transfronteiriça da WCPA; EUROPARC Federation e sua rede, TransParcNet, com importante representatividade 
na Europa; Peace Parks Foundation, principal atuação na África; UNESCO, especialmente com os Sítios do Patrimônio e Reservas da Biosfera; e outras ONGs internacionais como Conservation Internacional, The Nature Conservancy, UNEP, InWent, WWF e ITTO. O Global Transboundary Conservation Network reúne especialistas no tema e faz a ponte mundial entre organizações. Essas instituições contribuem tanto para a implementação de projetos de cooperação transfronteiriça como para o desenvolvimento de conceitos e abordagens. Uma das maiores contribuições é o estabelecimento de diretrizes e ferramentas de avaliação e monitoramento para as iniciativas (Quadro 1).

Quadro 1 - Principais diretrizes, ferramentas e certificação disponíveis para conservação transfronteiriça.

\section{Diretrizes}

1. Transboundary Protected Areas for Peace and Cooperation (SANDWITH et al., 2001).

2. Beyond Boundaries: Transboundary Natural Resource Management (LINDE et al., 2001).

3. Security in Planning and Management of TBCAs (BRAACK et al., 2006).

4. Enhancing our Heritage Toolkit - Assessing management effectiveness of natural World 5. Heritage sites (HOCKINGS et al., 2008).

5. International cooperation: Guidelines for International Cooperation under the Ramsar Convention on Wetlands - Ramsar Handbook 20 (RAMSAR CONVENTION SECRETARIAT, 2010).

6. Initiating effective transboundary conservation (ERG et al., 2012 - WWF/WCPA). Algumas das estratégias são adaptadas do Working Across Boundaries: People, Nature, and Regions (McKINNEY; JOHNSON, 2009).

\section{Ferramentas}

7. Ambiente de E-learning do Programme of Work on Protected Areas (Módulo 3 Disponível em: https://www.cbd.int/protected/e-learning/default.shtml).

- Rapid Assessment and Prioritization of Protected Area Management (RAPPAM) Methodology (ERWIN, 2003).

- Review of Experience with Ecological Networks, Corridors and Buffers Zone (BENNETT; MULONGOY, 2006).

- Evaluating Effectiveness: A framework for assessing management effectiveness of protected areas (HOCKINGS et al., 2006).

8. Diagnostic tool for transboundary planning conservation (ERG et al., 2012 WWF/WCPA).

\section{Certificação}

9. Transboundary Parks - Following nature's design (EUROPARC Federation, 2003).

Fonte: Org. dos Autores, 2018. 


\section{Contexto histórico e institucional}

A cooperação transfronteiriça na Europa expandiu nos últimos 30 anos, mas sua concepção é mais antiga. Durante milênios houve uma intensa manipulação na delimitação das fronteiras políticas através das disputas territoriais por meio de guerras intra e inter continentais. Por este histórico, o estabelecimento de áreas protegidas em fronteiras na Europa está fortemente relacionado a aspectos históricos e políticos, mais do que ecológicos ou ambientais. O Século XX foi uma das etapas mais intensas de redefinições territoriais de nações no continente europeu. Entre e após as duas Grandes Guerras (1914-18,1939-45), os limites fronteiriços das unidades políticas nacionais e subnacionais existentes foram reiteradamente modificados.

Entanto, na América do Sul os conflitos territoriais fronteiriços desencadearam frequentes guerras internacionais no Século XIX (HALPERIN DONGHI, 2010) e no início do Século XX, porém em uma escala mais restrita que os conflitos bélicos europeus ao longo do mesmo século. Na última década acabou um dos últimos conflitos bélicos sulamericanos: o Tratado de Brasília (1998) pôs fim à Guerra do Cenepa entre Peru e Equador (1995-1998). Na mesma década, na Europa desenvolvia-se uma fase mais da longa e antiga Guerra dos Balcãs. A partir de então, as disputas territoriais entre Estados Nacionais foram dirimidas através de negociações bilaterais, colocadas em mediação supranacional regional na UNASUR, e naquelas em aberto, nos organismos internacionais de segurança e justiça global.

Na Europa, por outro lado, a queda da Cortina de Ferro, simbolizada na demolição do muro de Berlim (1989), significou a emergência de novos estados nacionais e o regresso de outros ao cenário geográfico, político e comunitário europeu (HOBSBAWM, 2014). Intensificaram-se conflitos territoriais e separatistas resultando no aparecimento de novos estados. 
Devido a estes processos históricos e aos atuais conflitos territoriais, pode-se inferir que a gestão conjunta de parques nacionais continua sendo um importante mecanismo institucional coadjuvante para a preservação de relações pacíficas entre países vizinhos nesse continente. Os gestores europeus entrevistados corroboram essa visão e ressaltam que a existência de muitos países pequenos também contribui nesse sentido.

\begin{abstract}
Uma razão que é bem simples é porque aqui na Europa os países são relativamente pequenos. É uma razão simples e lógica, é uma razão política. Tudo deve estar entre fronteiras, estar transnacionalmente na Europa, essa é uma razão. Eu acho que na Áustria nós tivemos uma situação específica: a razão política. Por muitas décadas depois da Segunda Guerra Mundial, a Europa foi dividida em Europa Ocidental e Europa Oriental. E essa região de fronteira era a Cortina de Ferro, onde as áreas não estavam desenvolvidas, pois existiam grandes defesas e as fronteiras estavam fechadas. Após a Cortina de Ferro habitats valiosos ainda existem, e o Green Belt mostrou interesse na importância dessas antigas áreas do Cortina de Ferro (Gestor 1, Austríaco).
\end{abstract}

A Cortina de Ferro representa uma das barreiras mais emblemáticas existentes, representando a ambiguidade entre natureza e cultura. Por mais de 40 anos (1949-1989) afastou as pessoas ao longo de linhas políticas sustentadas por distintas ideologias, causando grande impacto sobre a vida cultural, social e econômica. Nenhuma atividade era permitida na zona proibida ao longo desta barreira. Por outro lado, os atributos ecológicos, desrespeitando as normas humanas, resultou imprevistamente em um grande cinturão verde na antiga linha de fronteira, representando a única herança positiva da Guerra Fria. Este fato possibilitou o nascimento do Green Belt, uma iniciativa para integração de áreas, seus habitat-chave e suas áreas ecológicas, como parte de uma rede internacional de ecossistemas, por um lado, e por outro, com o objetivo de formar uma identidade da união entre o leste e oeste europeu. IUCN, UNESCO e EUROPARC Federation apoiam essa estratégia.

A existência de instituições não governamentais fortes também 
possibilita uma pressão ao governo e um apoio aos gestores no estabelecimento das propostas de conservação transfronteiriça. Ademais, verifica-se que a União Europeia, enquanto modelo de integração políticoeconômica, auxilia na construção do senso de unidade e na flexibilização fronteiriça sustentada pelo Acordo Schengen, contribuindo para que as fronteiras, ideológicas, políticas ou econômicas, sejam mais maleáveis, apesar deste ser um fator (liberação fronteiriça) não preponderante para a cooperação para os entrevistados.

Os recursos, estratégias e ações relacionados às áreas protegidas transfronteiriças podem ser reflexos de um pensamento onde as fronteiras devem ser cada vez menos importantes a fim de se criar um sentido de unidade europeia e não de conservação propriamente dita. Segundo Ferreira (2005), inicialmente, os tratados fundacionais que instituíram a integração europeia objetivavam apenas o aspecto econômico. Ao instituir uma cidadania comunitária através do Tratado de Maastricht (1992), e reforçado pelo Tratado de Amsterdã (1997), a União Europeia buscou criar uma identidade comum aos povos de seus Estados-membros, atribuindo direitos e deveres inerentes à qualidade de cidadão comunitário. Isso contém aspectos de uma geopolítica que por traz de interesses econômicos coloca a conservação como política exterior. Esse sentimento de unidade reflete-se na criação do Acordo Schengen (1985), que mesmo não sendo vinculado diretamente à União Europeia, acaba influenciando-a.

Um dos gestores não considera que o Acordo Schengen afete a administração de sua área protegida ou a cooperação estabelecida. O interessante é que entre esses parques há uma normativa que institui que os visitantes não podem cruzar as suas fronteiras, pois o plano de manejo foi concebido de forma a alocar a zona intangível nesta região. Portanto, a lei regente dos parques sobressai ao Acordo.

O Acordo Schengen é só para atravessar as fronteiras, mas nos parques você não pode... claro que você poderia poderia andar pelo 
rio; é proibido na verdade não pelo Schengen, mas pela administração do parque nacional. Porque ambos os lados concordaram que os visitantes só podem andar pelas partes permitidas de caminhada... Mas não afeta a nossa administração (Gestor 2, Austríaco).

A gestão binacional de áreas naturais protegidas na experiência europeia é em parte resultante direta dos mecanismos institucionais de integração supranacional. No contexto Sul Americano, a relação entre mecanismos institucionais e acordos de gestão binacional de áreas naturais protegidas também existe, porém, esta vinculação é indireta e a institucionalidade gerada por estes mecanismos não é equivalente. Antecedentes de debates políticos a respeito da necessidade de integração política regional sul americana podem ser rastreados desde as lutas pelas independências do início do Século XIX. Durante o Século XX esta necessidade aparece como demanda de movimentos e lideranças políticas em países da região, sendo cancelado este debate na segunda metade do século pela instabilidade política caracterizada pelas ditaduras militares na região, adversas aos mecanismos de integração regional por conta de paradigmas de defesa da integridade territorial sobre a ideia de hipótese de conflito (PEIXOTO; LOZA, 2006).

Desde o final do Século XIX até a segunda metade do Século XX, os territórios de fronteira e as cidades neles situadas se destacaram geopoliticamente com o intuito de fortalecer a soberania territorial nacional. Nas décadas de sessenta a noventa se dá o auge da criação de áreas naturais protegidas nos países sul americanos chegando a cobrir, em 2011, aproximadamente $13 \%$ do território regional, sem incluir áreas costeiras protegidas (GONZÁLEZ-CELIS, 2013). Já nos governos da recuperação democrática, a importância dessas cidades tinha mais vinculação com objetivos de integração comercial transfronteiriça (PEIXOTO; LOZA, 2006).

Igual ao ocorrido na Europa, na década de noventa, foram criados na América do Sul mecanismos institucionalizados de integração transnacional. 
É o caso do Mercado Comum do Sul (MERCOSUL), criado pelo Tratado de Asunción (1991), focado na integração aduaneira e facilitando o trânsito de bens e serviços. No entanto, não aparecem preocupações sobre gestão conjunta do patrimônio natural dos Estados Parte fundadores (Brasil, Argentina, Paraguai e Uruguai) ou de políticas de conservação específicas dos ecossistemas comuns. O Acordo-Quadro sobre Meio Ambiente (2001) no Capítulo III fala sobre "Cooperação em matéria ambiental" entre os Estados Membros. O foco está colocado na "harmonização das legislações ambientais" e não há menção expressa de cooperação em áreas naturais transfronteiriças.

No início do Século XXI os objetivos da integração se ampliam visando favorecer a integração política, social e cultural, por conta do impulso dos governos progressistas na região. Com a criação da UNASUR (União de Nações Sul-Americanas), em 2007, aparecem preocupações conservacionistas e interesses para criar mecanismos similares ao Acordo Schengen, mas o foco diferencial é a "defesa dos recursos naturais" no plano da "segurança regional" contra possibilidades eventuais destes serem alvos de exploração por parte de outros países ou blocos regionais do mundo (UNASUR, 2015).

\section{Aplicabilidade e recomendações}

É quase consenso no discurso apresentado pelos gestores que a conservação da biodiversidade é o principal objetivo para criação dessas áreas, seja para protegê-las, pelo entendimento de que de que 'natureza não tem fronteira', ou pelo pelo valor ecológico das áreas, seja pelo direito de existência dos seres que ali habitam, pela salvaguarda de recursos importantes da região ou para garantir um tamanho de área adequado para atingir os valores anteriores. Outros objetivos identificados são: Estabelecimento de Parcerias, no sentido de: a) cooperar para conservar e b) 
cooperar para criar identidade comum. Herança e Histórico comum, Renda e Turismo também apareceram como objetivos, embora de forma pontual no discurso dos gestores.

Também foi solicitado que indicassem, em ordem de importância, os objetivos, esferas de benefícios e aspectos dificultadores apontados por Lim e Rosen (2012), como resultados de survey realizado com membros de grupo de especialistas em conservação. A Conservação da biodiversidade continua ocupando a primeira posição, mas não é uma unanimidade. Dois gestores citaram o Desenvolvimento sustentável e outro a Cooperação como objetivo primordial. Esses dois objetivos também aparecem na segunda posição de importância. Em relação aos outros objetivos não houve consenso, entretanto, Redução da pobreza e Restituição pela posse da terra parecem ter menos sentido para os gestores como objetivo em criar uma área protegida transfronteiriça, provavelmente por não serem questões importantes na realidade europeia como seria no Brasil.

Os benefícios, apesar de diretamente relacionados aos objetivos, não seguiram a mesma homogeneidade das respostas no que concerne à biodiversidade, ou seja, os gestores consideram a conservação da biodiversidade como o principal objetivo para criar uma área protegida transfronteiriça, mas as Pessoas são as principais beneficiadas. O benefício pessoal se traduz: a) individualmente, possibilitando maior autoconsciência e aprendizado, b) na relação com os pares, através da troca e da amizade e, c) para o visitante, transmitindo informação. Pesquisa, Gestão, Economia parecem ser beneficiados de maneira equivalente e, por fim, a esfera Política não seria tão beneficiada com a cooperação.

As maiores dificuldades na gestão de uma área protegida transfronteiriça, no discurso dos gestores, estão visibilizadas em elementos que podem tornar o trabalho mais cansativo, pela burocracia e diferenças na coordenação das ações entre diferentes instituições políticas. As diferentes legislações, categorias de conservação, recursos e a barreira idiomática, 
principalmente entre falantes de tcheco e alemão, também foram incluídos. No confronto com as dificuldades apontadas por Lim e Rose (2012), a indiferença política e diferentes dispositivos legais foram considerados os maiores elementos dificultadores. Diferenças culturais, níveis de competência profissional e estágios de desenvolvimento econômico de cada país envolvido são menos importantes na visão dos gestores.

O entusiasmo ou motivação para a cooperação transfronteiriça varia de acordo com as pessoas e não é homogênea entre os entrevistados. Isso demonstra uma consciência que na realidade diária é preciso lidar também com as diferenças inter-pessoais, que são mutáveis ao longo do tempo. Entretanto, de uma forma geral, os gestores têm uma opinião positiva em relação aos parceiros, sendo possível observar o contágio motivacional em ambos os lados da fronteira e sua importância para a manutenção da iniciativa transfronteiriça.

As impressões unânimes dos gestores sobre o processo de certificação foram de que esta surgiu como consequência da cooperação preexistente, a partir de necessidades reais de resolução de problemas relacionados à conservação das áreas protegidas. Ressaltam que a certificação é mais importante pelo processo desencadeado, por instituir um sistema de autoavaliação e não pelo certificado em si. Quanto a esse aspecto, é interessante a menção de um dos gestores de que a certificação mantém a cooperação na instituição, de maneira que mudanças de gestão não comprometem a iniciativa. Com isso, se mantém independente dos diferentes interesses que possam surgir.

Os gestores do Triglav, Parco Prealpi Giulie e Krokonose informaram que a população local participa da gestão através do conselho oficial do parque, em sua maioria consultivos. Não é possível dizer se nas outras áreas não há conselho ou se não foi informado pelos gestores, pois, por exemplo, enquanto o gestor do Krokonose afirma que todos os parques da República Tcheca têm conselhos, o gestor do Bohemian, outro parque tcheco, não citou 
essa informação. Para ele, a participação não ocorre diretamente, mas através de consultas pontuais como o que foi realizado durante o processo de certificação.

No caso do Parque Donau Auen a participação se daria apenas na medida em que as pessoas visitam a área do parque e em eventos culturais ou científicos patrocinados. O gestor considera difícil incluir a população em decisões de um projeto de alcance transnacional, devido à sua inerente complexidade. Em outro parque austríaco, o Neusiedler See, caracterizado como um conjunto de reservas particulares do patrimônio nacional (RPPN), quando comparado ao sistema brasileiro, a população afeta diretamente a gestão, pois os donos da terra aderem por livre e espontânea vontade ao conjunto e, segundo o gestor, a partir do momento que se tem um contrato eles conhecem os limites e possibilidades no uso da terra.

O tema conflito foi mencionado pelo gestor do Krokonose, trazendo reflexões interessantes à realidade vivida pelo parque na relação com a comunidade e à solução encontrada para minimizar as tensões pelo uso do espaço. No discurso do gestor destacam-se os temas disputa pela terra, medo de desapropriação e falta de diálogo como causas principais geradoras de conflito. Por outro lado, a transparência das ações, a evocação do conflito, o diálogo direto dos gestores com a comunidade e definição de regras parecem ser as soluções encontradas para formar uma aliança na gestão da área.

Os gestores têm opiniões contraditórias sobre a importância da conservação da natureza em seus países. A princípio existem boas leis e recursos, mas quando questões econômicas entram em jogo, como uma crise ou implementação de empreendimentos, esses são mais apoiados pelo governo em detrimento da conservação. Outro ponto citado é a conservação enquanto propulsora do turismo, o que não deixa de ser um apelo econômico. Por último, foi citada a mudança da situação política e as decisões tomadas top-down como dificultadoras da implementação de ações conservacionistas. Os gestores recomendaram aspectos considerados primordiais para os 
interessados na iniciativa transfronteiriça: os elementos da interação entre as pessoas, como motivação e percepção do vizinho, bem como um mútuo entendimento dos objetivos e necessidades, aliados ao contexto político.

Conhecer essas áreas protegidas transfronteiriças certificadas e entrevistar seus gestores contribui para ampliar a compreensão quanto à prática da cooperação e dá sentido ao significado de conceitos por vezes abstratos, como os de cooperação e patrimônio. Isto pode ser útil para os estudos em matéria de gestão cooperativa binacional de áreas protegidas transfronteiriças locais, como o caso do Parque Nacional do Iguazú e Iguaçu. Criados em 1934 e 1939, respectivamente, e localizados na fronteira entre Argentina e Brasil. Em conjunto abrigam o maior remanescente de floresta estacional semidecidual, atravessado pelo rio Iguaçu, fronteira entre ambos países. Por conta da expressiva variabilidade biológica, somada à beleza cênica das Cataratas do Iguaçu, os parques são Sítios do Patrimônio Mundial Natural pela UNESCO desde 1984 (Iguazú) e 1986 (Iguaçu).

Kropf e Eleuterio (2017) verificaram que os gestores desses parques possuem uma visão do patrimônio natural apenas enquanto entidade ecológica, que conforme Zanirato e Ribeiro (2006) se caracteriza menos por permitir uma identidade a quem nele vive, mas sim pelos atributos que lhe conferem beleza cênica e possibilidade de novas experiências. Cabe ressaltar que a escolha do conceito "patrimônio natural" e não "recurso natural" baseia-se em uma decisão epistemológica. O último termo conota um significado de mercantilização e subserviência da natureza à produção de bens e serviços. A ideia de conservação tem mais coerência com o conceito "patrimônio", pois ele é compartilhado entre gerações (FERRO, 2011).

Esta definição de patrimônio cultural ou natural é complexa, pois constituem uma representação da dicotomia da relação sociedade-natureza. Afinal o que é um sítio natural sabendo-se que a natureza por si e enquanto definição é uma construção social? Zanirato e Ribeiro (2006) argumentam serem os bens materiais e imateriais, tangíveis e intangíveis que 
compreendem o patrimônio cultural, manifestações ou testemunho significativo da cultura humana, imprescindíveis para a conformação da identidade cultural de um povo. Pois, se tratando do patrimônio natural, a avaliação é ainda maior, posto ser a salvaguarda dos recursos materiais e do conhecimento tradicional sobre os usos desses recursos, essencial para a garantia de uma vida digna para a população humana.

Pelegrini (2006) também enfatiza a apresentação fragmentada do conceito de patrimônio, mas verifica a construção de entendimento de interrelacionamento entre patrimônio cultural e ambiental, ou seja, independentemente das suas respectivas categorias, todo o patrimônio se configura e se engendra mediante suas relações com a cultura e o meio, inserindo no patrimônio ambiental dimensões sociais, de sentidos decorrentes do processo histórico, com perspectiva dinâmica e conotação que fomenta a consciência do uso comum do meio e, principalmente, a responsabilidade coletiva pelo espaço.

\section{Considerações Finais}

Verificou-se que a estratégia de implantação de áreas protegidas em fronteiras europeias está relacionada a três fatores: (1) às histórias de guerras entre os países; (2) existência de poucos remanescentes florestais nesses locais, outrora vazios humanos e; (3) ameaça de extinção de muitas espécies. A história comum dos países europeus está relacionada por conflitos, devido a disputas territoriais entre Estados e no interior destes. A gestão cooperativa transnacional de áreas protegidas transfronteiriças parece ajudar a criar um objetivo comum, sendo a cooperação e promoção de paz um elo importante nessa relação. No aspecto geopolítico, as áreas protegidas de conservação do patrimônio natural sob gestão cooperada podem contribuir à consolidação das relações pacíficas entre Estados nacionais europeus e também sul americanos, porque implicam 
estruturalmente a gestão dos territórios além do patrimônio natural e a possibilidade de melhor convivência das diversidades culturais, lingüisticas e étnicas.

A cooperação entre as áreas tem como foco a conservação da biodiversidade devido ao compartilhamento do mesmo habitat. Entretanto, os maiores benefícios parecem estar na troca de experiências entre os gestores, tirando-os do isolamento e criando uma rede de aprendizado intercultural. A percepção dos gestores em relação à dimensão socioeconômica das parcerias é menos significativa do que os benefícios oriundos da parceria intercultural. As forças motrizes para ultrapassar as dificuldades são a consciência da importância do trabalho conjunto e o senso de unidade. Um aspecto a destacar é a necessidade de uma definição legal e um contexto político apropriado para manter as iniciativas cooperadas.

A certificação, da forma que é conduzida pela EUROPARC Federation, ao formalizar vínculos preexistentes, ajuda a consolidar uma identidade de cooperação que é a força motriz para a manutenção das relações ao longo do tempo.

$\mathrm{O}$ valor dado à cultura regional e local contribui para manutenção da identidade de cada área, resultando numa paisagem realmente socio-biodiversa. Em um quadro de um crescente multiculturalismo, a ultrapassada ideia de uma sociedade cultural e etnicamente homogênea se encaixa apenas dentro de uma política conservadora e xenofóbica. A experiência da partilha da gestão das áreas de conservação transfronteiriças, a parte das dificuldades e desafios aqui expostos, reafirma a importância da paisagem e de sua gestão em uma política ampla, como a da União Europeia, que tenta suprimir muitas de suas barreiras e fronteiras. 


\section{Agradecimentos}

Agradecemos à Petra Schultneiss da Europarc Federation e aos gestores das áreas protegidas visitadas. Ao CNPQ/ Programa Ciência sem Fronteiras pela concessão de bolsa de doutorado sanduiche para a primeira autora e de produtividade em pesquisa para o terceiro. Ao Instituto de Ecologia Social (Universidade de Klagenfurt), em especial, à Verena Winiwarter, pelo suporte e supervisão da pesquisa.

\section{Referências}

BARDIN, L. Análise de conteúdo. Lisboa: Edições 70, 1977.

BRAACK, L. et al. Security Considerations in the Planning and Management of Transboundary Conservation Areas. Gland, Switzerland and Cambridge: IUCN, 2006.DANBY, R.K. International transborder protected areas: experience, benefits, and opportunities. Environments, v. 25, n. 1, p. 3-14, 1997.

EC.EUROPA.EU. 0 programa LIFE. Disponível em: http://ec.europa.eu/environment/basics/natural-capital/life/index_pt.htm. Acesso em: 02 de mai. 2018.

EUROPARC FEDERATION. Transboundary Parks - Following the nature design: a tool for improving transboundary cooperation in europe. Grafenau, Germany, 2003.

ERG, B. et al. (eds.). Initiating effective transboundary conservation: A practitioner's guideline based on the experience from the Dinaric Arc. Gland, Switzerland and Belgrade, Serbia: IUCN Programme Office for South-Eastern Europe, 2012. 98p.

FERRO, S.L. La tierra en Sudamérica. Serie Exploraciones 8 Desarrollo Rural. La Paz: Instituto Rural para el Desarrollo Rural de Sudamérica, 2011.

GOES FILHO,S. S. As fronteiras do Brasil. Brasília: FUNAG, 2013.

GONZÁLEZ-CELIS, G.L. El derecho ambiental en la integración regional de Suramérica. Letras Verdes. Revista Latinoamericana De Estudios Socioambientales, n. 12 (octubre), p. 42-56, 2013. https://doi.org/10.17141/letrasverdes.12.2012.923

HALPERIN DONGHI, T. Historia Contemporànea de Amèrica Latina. Buenos AiresMadrid: Alianza Editorial, 2010.

HAMILTON, L.S. et al. Transborder Protected Area Cooperation. Gland and Switzerland: IUCN/Australian Alps National Parks, 1996.

HOBSBAWM, E. Era dos extremos.O breve século XX.1914-1991. São Paulo: Companhia das Letras, 2014.

HOCKINGS, M. et.al. Enhancing our Heritage Toolkit: Assessing management effectiveness of natural World Heritage sites. Paris: UNESCO World Heritage Centre, 2008.

IRVING, M.A. Parque Nacional Montanhas de Tumucumaque (AP- Brasil): "ultraperiferia" ou "laboratório" para a cooperação em gestão da biodiversidade nos espaços amazônicos de fronteira? Revista de Desenvolvimento Econômico, n. 10, p. 26-37, 2004.

IUCN. Resolutions and Recommendations. Montreal: IUCN World Conservation Congress, 1997.

KROPF, M.S.; ELEUTERIO, A.A. Histórico e perspectivas da cooperação entre os parques nacionais do Iguaçu, Brasil, e Iguazú, Argentina. RELEA, v.1, n.1, p.5-25, 2017. 
KROPF, M.S.; OLIVEIRA, R.R. Áreas protegidas Fronteiriças. Perspectiva Geográfica (Impresso), v. 8, n. 9, 2013.

LIM, M.; ROSEN, T. Results of legal concept paper survey. Disponivel: http://www.tbpa.net/additionaldocs/Results\%20of\%20Legal\%20Concept\%20Paper\%20Surve y_May\%202012.pdf. Acesso em: 15 de jan. 2013.

LINDE, H. et al. Beyond Boundaries: Transboundary Natural Resource Management in Sub-Saharan Africa. Washington, D.C.: Biodiversity Support Program, 2001.

McKINNEY, M.J.; JOHNSON, S. Working across Boundaries: People, Nature, and Regions. Cambridge: Lincoln Institute Of Land Policy, 2009.

MITTERMEIER, R.A et al. Transboundary Conservation. A New Vision for Protected Areas. CEMEX-Agrupación Sierra Madre-Conservation International, Mexico, 2005.

NVIVOQUALITATIVE data analysis Software. QSR International Pty Ltd.Version 10. 2012.

PEIXOTO, J.; LOZA, J. La relación Argentina-Brasil: entre la administración de conflictos y las políticas de cooperación. Estudios, n. 18, Córdoba: Universidad Nacional de Córdoba, 2006.

PELEGRINI, S.C.A. Cultura e natureza: os desafios das práticas preservacionistas na esfera do patrimônio cultural e ambiental. Revista Brasileira de História, São Paulo, v. 26, n. 51, p. 115-140, 2006. https://doi.org/10.1590/S0102-01882006000100007

RAMSAR CONVENTION SECRETARIAT. International cooperation: Guidelines and other support for international cooperation under the Ramsar Convention on Wetlands. Ramsar Convention Secretariat, Gland, Switzerland. Ramsar handbooks for the wise use of wetlands, 4th edition, v. 20, 2010.

SANDWITH, T. et. al. Transboundary protected areas for peace and co-operation. Gland and Cambridge: IUCN, 2001.

SLOCOMBE, D.S; DANBY, R.K. Transboundary Protected Areas, Connections and Conservation. Transboundary Protected Areas: Research and Planning, p. 7-18, 2006.

SMITH, R.D.; MALTBY, E. Using the Ecosystem Approach to Implement the Convention on Biological Diversity: Key Issues and Case Studies. IUCN, Gland, Switzerland and Cambridge, 113p. 2003. https://doi.org/10.2305/IUCN.CH.2003.CEM.2.en

UNASUR. Estudio Prospectivo Suramérica 2025. Primera Parte. Buenos Aires: CEED. Consejo de Defensa Suramericano, 2015.

UNEP-WCMC. Global List of Transboundary Protected Areas. Disponível em: $<$ http://www.tbpa.net>. Acesso em: 5 nov. 2013.

VASILIJEVIĆ, M. Transboundary conservation areas: History and global trends. In: ERG, B. et al. (eds.). Initiating effective transboundary conservation: A practitioner's guideline based on the experience from the Dinaric Arc. Gland, Switzerland and Belgrade, Serbia: IUCN Programme Office for South-Eastern Europe, 2012. 98p.

ZANIRATO, S.H.; RIBEIRO, W.C. Patrimônio cultural: a percepção da natureza como um bem não renovável. Revista Brasileira de História, São Paulo, v. 26, n. 51, p. 251-262, 2006. https://doi.org/10.1590/S0102-01882006000100012

ZBICZ, D. Global List of Complexes of Internationally Adjoining Protected Areas. In: SANDWITH, T. et al. Transboundary Protected Areas for Peace and Cooperation. Gland, Switzerland and Cambridge: IUCN, 2001. 